\title{
Radial growth trends of loblolly pine in the Virginia Coastal Plain
}

\author{
Gregory A. Reams
}

\begin{abstract}
A number of recent studies have shown reduced individual-tree growth throughout the 1970s and early 1980s in natural loblolly pine (Pinustaeda L.) stands in the southeastern United States. This study updates radial growth trends of loblolly pine in the Virginia Coastal Plain through 1989. Ring-width series were initially grouped into two age-classes ( $<50$ or $\geq 50$ years) and a clustering procedure was used to identify common radial growth patterns. These data suggest that radial growth trends of loblolly pine are cyclic and support previous findings of reduced growth in the $1970 \mathrm{~s}$. A reversal in trend has occurred since the early 1980s with radial growth increasing since then for both old and young trees. This change to increased growth corroborates the finding of increased growth of loblolly pine identified in the most current Forest Inventory and Analysis (FIA) survey cycle for the Virginia Coastal Plain.
\end{abstract}

Résumé : Plusieurs etudes rtcentes ont rapporté une reduction de la croissance des arbres au cours des années 1970 et au debut des années 1980 dans les peuplements naturels de pin à encens ( Pinustaeda L.) du sud-est des Stats-Unis. Cette etude met à jour les tendances qui se manifestent dans la croissance radiale du pin à encens de la plaine côtière de la Virginie jusqu'en 1989. Des series de largeurs de cernes ont d'abord étéregroupées en deux classes d'âge ( $<50$ ou $\geq 50$ ans) et une analyse de regroupement a étéutilisée pour détecter les patrons similaires de croissance radiale. Ces données suggtrent que les variations dans la croissance radiale du pin à encens sont cycliques et supportent les observations anttrieures de reduction de croissance dans les années 1970. La tendance s'est renversée depuis le debut des années 1980 et la croissance radiale a augment6 depuis ce temps autant chez les jeunes que chez les vieux arbres. Ce changement, qui se manifeste par une augmentation de croissance. corrobore l'augmentation de croissance du pin à encens identifiée dans le plus recent cycle d'inventaire du programme d'analyse et d'inventaire des forêts pour la plaine côtière de la Virginie.

[Traduit par la Redaction]

\section{Introduction}

A number of recent studies have shown reduced growth of natural loblolly pine (Pinustaeda L.) in the southeastern United States. Because these studies (Sheffield et al. 1985; Zahner et al. 1989; Ruark et al. 1991; Bechtold et al. 199 I: Van Deusen 1992a) are based on data collected in the early 1980s updating trends in radial growth are of interest from both a scientific and economic basis. Many foresters involved with forest health and productivity issues are curious as to whether growth rates have improved in the interim or continued to decline.

Important issues involving forest health and productivity and the possible deleterious effects that air pollutants have on forests have not been confined to the southeastern United States. This issue has stimulated much research in Europe and North America over the past decade. In response to forest health concerns, an interagency work group between the USDA Forest Service and the US Environmental Protection Agency (EMAP-Forests) was set up in 1989 to conduct pilot tests concerning evaluation of indicators of forest health and condition. In 1990. the Virginia

Received June 19, 1995. Accepted May IO, 1996.

G.A. R eams. USDA Forest Service, Institute for Quantitative Studies, Southern Research Station, 701 Loyola Avenue, New Orleans. LA 70113, U.S.A.
$20 / 20$ study was implemented as a pilot study so that a preliminary set of measurements could be tested for the Forest Health Monitoring (FHM) Program. Radial growth of trees has historical precedence as an indicator of forest health and productivity and was collected as part of the study. These radial growth data allow for one of the first published updates of loblolly pine growth since identification of growth declines in the early 1980s.

Updated trends in loblolly pine radial growth are particularly important given the data associated with identification of growth declines is in many cases over 10 years old (Sheffield et al. 1985; Zahner et al. 1989; Ruark et al. 199।; Bechtold et al. 1991; Van Deusen 1992a). The USDA Forest Service first noted growth reductions in 1982 during analyses of forest inventory data from Georgia. Subsequent analyses indicated that radial growth rates of pines in natural stands declined during the past $20-30$ years by $30-50 \%$ in Georgia, North Carolina, and South Carolina (Sheffield et al. 1985). In Virginia reductions in radial growth were confined to the Coastal Plain and were of lesser magnitude than in the previously mentioned states (Fig. I ).Lucier (1988) found no evidence of southern pine growth reductions on intensively managed forest industry lands.

The purpose of this paper is severalfold. First, to provide an update of loblolly pine radial growth since the previous USDA Forest Inventory and Analysis (FIA) survey cycle that was completed in the early 1980s. Second. to 
Fig. 1. Average annual radial increment by diameter class for loblolly pine growing in natural stands in the Coastal Plain of Virginia. Data for three survey periods are plotted. Data were provided by the Forest Inventory and Analysis Work Unit located in Asheville. N.C.

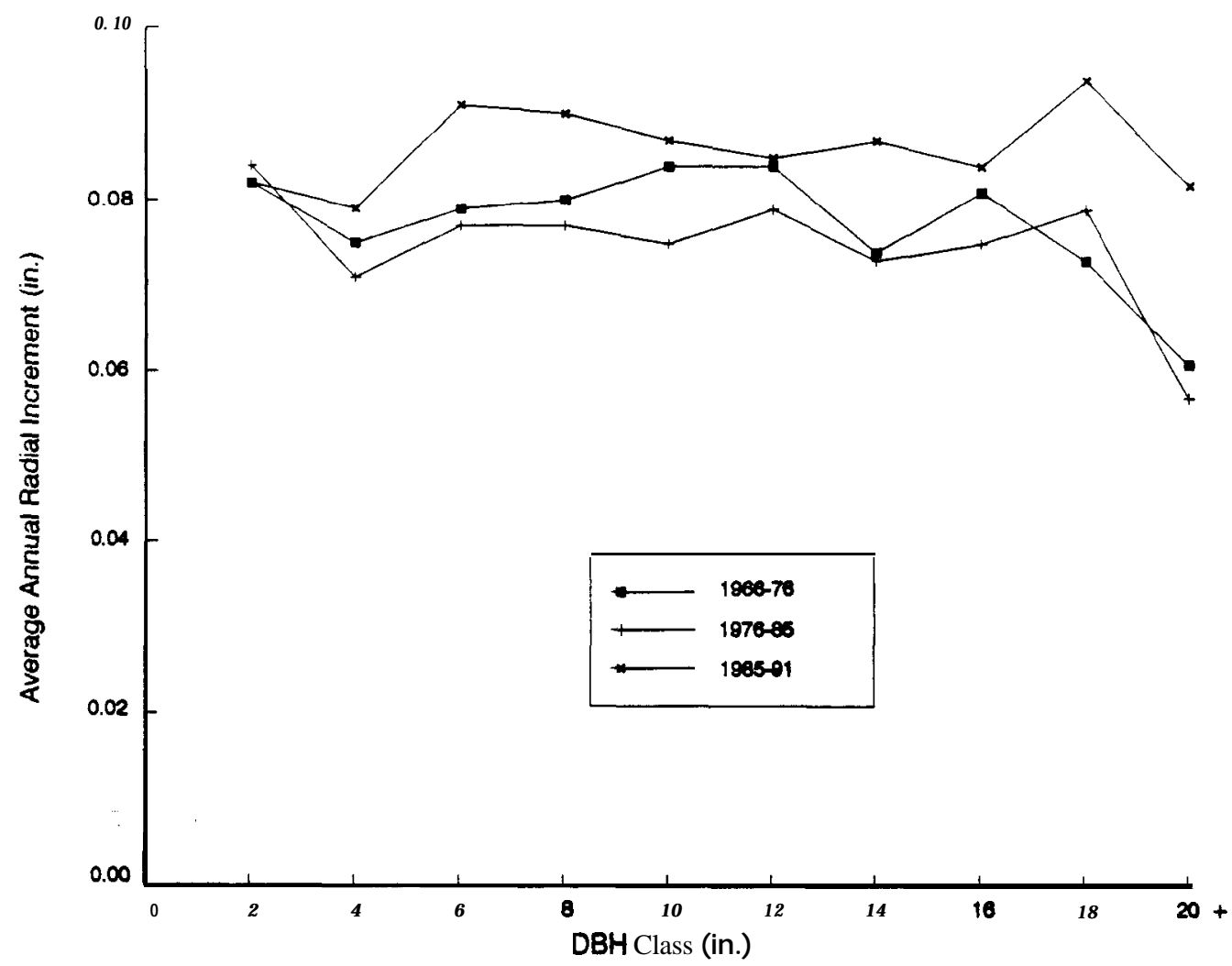

present a cluster analysis algorithm that identifies groups of radial growth patterns that are represented in these data. And finally, to openly speculate about some commonly suspected contemporary causes of changes in radial growth. However, because these are observational data with little environmental control the main purpose is to present the most prevalent individual tree growth trends rather than directly ascribe cause (Schreuder and Thomas 1991).

\section{Data}

A subset of 20 plots from the Virginia Coastal Plain were selected from the FHM design and measured in the summer of 1990 (Fig. 2). The FHM design consists of a randomly placed triangular grid covering the United States. The grid was established by arbitrarily positioning a pattern consisting of approximately 28000 hexagons of $635 \mathbf{~ k m}^{2}$ (each an individual hexagon) over an area somewhat larger than the lower 48 states of the United States. A point was randomly selected to occupy the same position within each hexagon to form the triangular grid. From each point of this grid, the nearest USDA FIA photo point is chosen for the location of a ground plot (Roesch 1995). The tree-ring data from the 20 plots sampled in this study represent loblolly pine - hardwoods forest types in the Coastal Plain of Virginia (Riitters et al. 1991).

Two increment cores per tree were extracted at breast height $(4.5 \mathrm{ft} ; 1 \mathrm{ft}=0.3048 \mathrm{~m})$ from four to six dominant or codominant loblolly pine trees per plot. If the sample tree was on a slope, the first core was extracted parallel with the slope. If the tree leaned, the core was extracted 90" from the lean. A second core was extracted 90" from the first core. The preparation of the tree cores involved drying, stabilizing the core by mounting it in a grooved strip of wood, and machine and hand sanding of the core so the annual rings were clearly visible, The ring widths were measured to the nearest $0.001 \mathrm{~mm}$ with an incremental measuring machine equipped with a linear encoder. The encoder was interfaced with a microcomputer that recorded ring widths by year.

Interactive cross-dating was achieved by using the crossdating program GRAFDATE, which is a component of the DYNACLIM tree ring analysis system (Van Deusen 19926). Cross-dating is the process by which each annual ring from an increment core is associated with its exact year of formation (Fritts 1976). This is possible because trees under similar climatic conditions show similar high-frequency (year to year) growth patterns (Douglass 1941).

A total of 192 cross-dated ring-width series from 96 (two cores/tree) trees were available for statistical analysis. The distribution of tree ages at breast height (Fig. 3) indicate that $67 \%$ of the trees originated between 1950 and 1969 . Approximately $21 \%$ of the trees are older than 50 years, with only $3 \%$ of the trees greater than 70 years.

\section{Methods}

Second-, third-, and fourth-degree orthogonal polynomials of the form Y $=b_{0} f_{0}(x)+b_{1} f_{1}(x)+b_{2} f_{2}\left(x_{2}\right)+b_{3} f_{3}\left(x_{3}\right)+b_{4} f_{4}\left(x_{4}\right)$, where the $f_{i}\left(x_{i}\right)$ are the orthogonal transformations in $\boldsymbol{x}$ (years $=$ $1, \ldots, 30)$ of the ith degree. were fit to the last 30 years (1960-1989) of radial growth for each ring-width series. The analysis could have been based on the average radial growth per 
Fig. 2. The 20-hexagon (plot) locations in the Coastal Plain of Virginia. The hexagons are not drawn to actual scale.

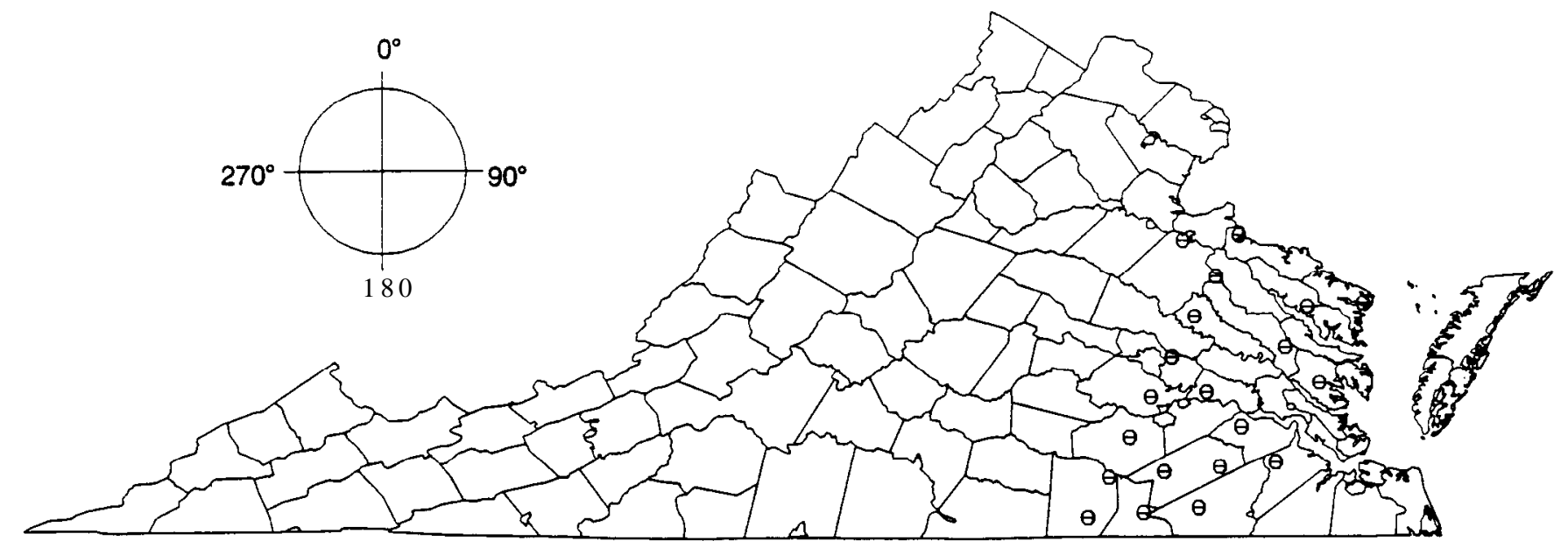

Fig. 3. Age distribution of loblolly pine in the Virginia 20/20 study.

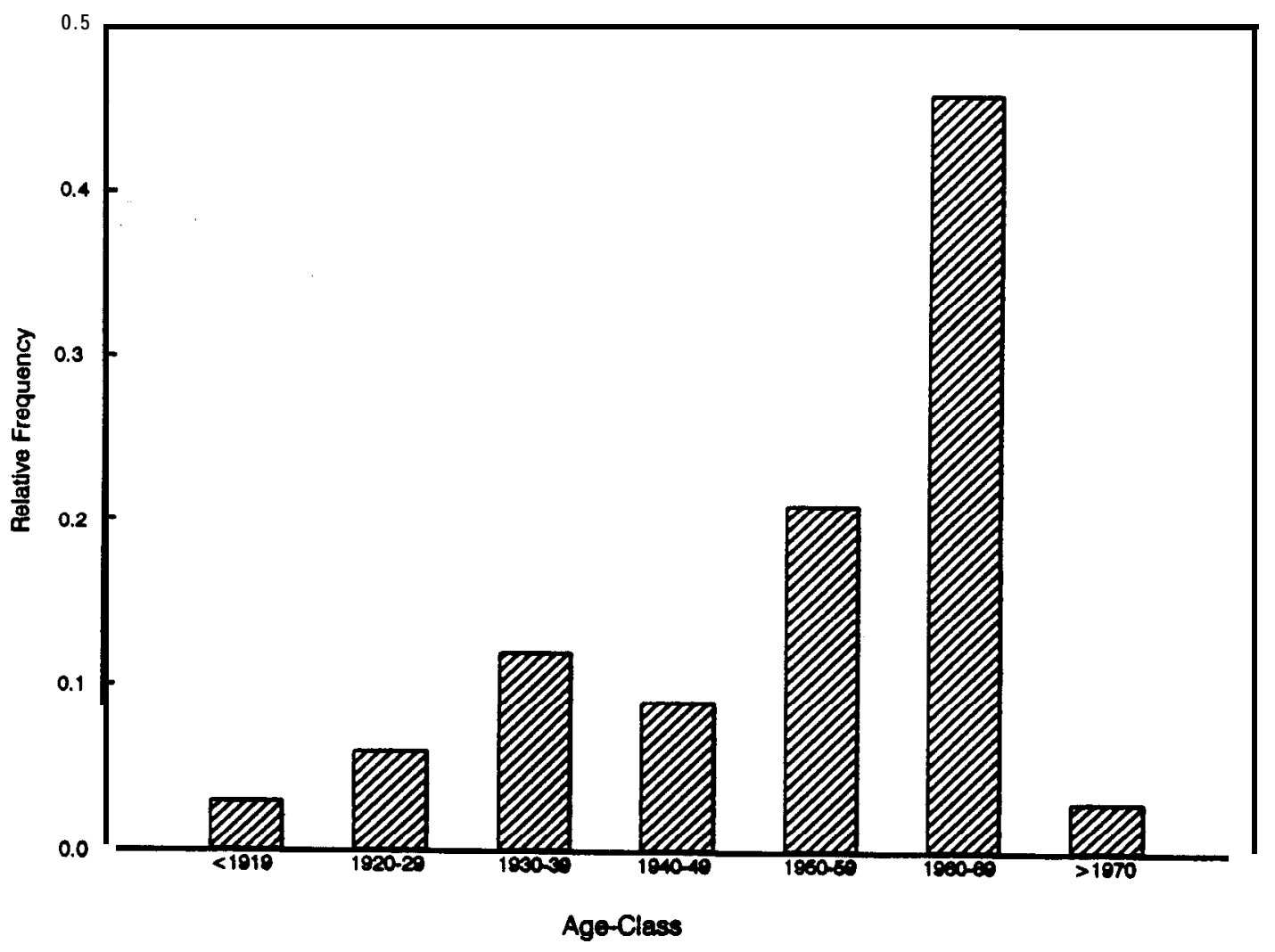

tree, however, doing so would not change the results. Because the basic goal is to classify the last 30 years of radial growth into groups with a similar growth curve, it makes little difference if the clustering algorithm classifies one or more growth patterns per tree as long as all trees are represented equally, as is the case for this study. The fitted coefficients for each tree-ring series were used as input to a clustering algorithm so that groups of growth curves could be identified. In this study the basic observed response is a growth curve rather than a single data point. Such an analysis is commonly referred to as functional data analysis (FDA) in the statistical literature (Ramsay and Dalzell 1991) and offers for a more natural analysis of growth trend information than would be provided by analyzing the actual yearly data points.

Clustering routines based on partitioning methods are particularly useful when characterization of the data are desired. Partitioning methods construct $\boldsymbol{k}$ clusters, with $\boldsymbol{k}$ given by the user. Not all values of $\boldsymbol{k}$ lead to natural clusterings, so it is recommended that several values of $k$ be selected and to use $k$ that retains clusterings that appear to give rise to the most 
Fig. 4. (A) Mean radial growth of loblolly pines greater than 50 years old. (B) Mean radial growth of loblolly pines less than 50 years old. (C) Mean radial growth of all loblolly pines in the Virginia 20/20 study.

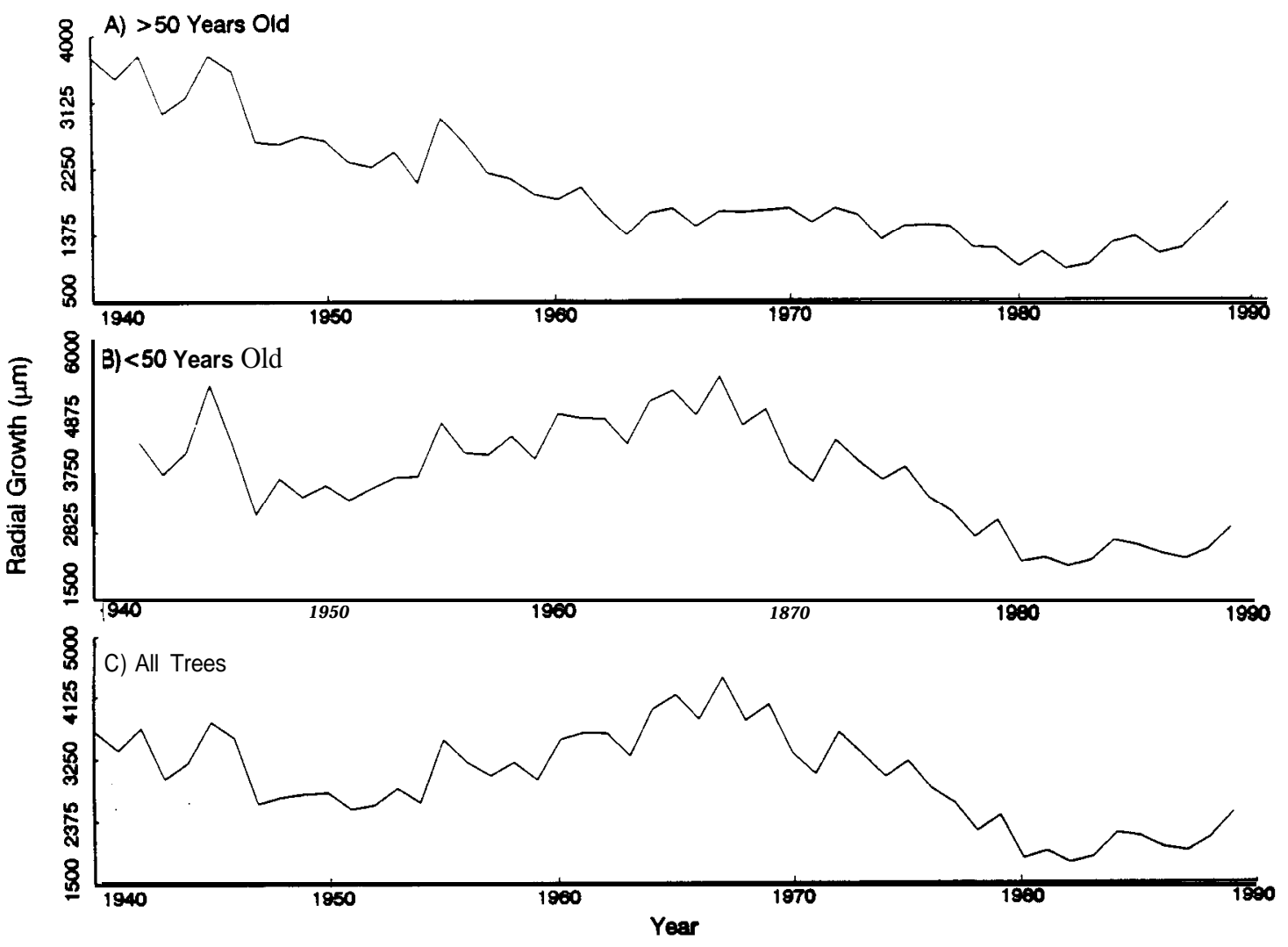

meaningful interpretations. It is also possible to choose $k$ that is judged best relative to a numerical criterion (Kaufmann and Rousseeuw 1990).

Clusters of growth patterns were identified using the algorithm PAM (Partitioning Around Medoids) which searches for $k$ representative objects among all objects in the data set. Representative objects in this study are the ring-width series of each increment core. After finding a set of $\boldsymbol{k}$ representative objects, the $k$ clusters are constructed by assigning each object of the data set to the nearest representative object. To achieve good clustering the representative objects must be chosen so that they are centrally located in the clusters they define, in this way the average distance of the representative object to all others of the same cluster is being minimized (Reams and Van Deusen 1993). For this reason, such an optimal representative object is called the medoid of its cluster (Kaufmann and Rousseeuw 1990). Readers interested in detailed discussions of cluster analysis should consult Kaufmann and Rousseeuw (1990).

\section{Results}

Since the early 1980s mean radial growth of trees in the Virginia 20/20 study appear to be increasing (Fig. 4) and represents a change in the long-term trend. Prior to the early 1980s, average radial growth for older trees ( $>50$ years) had been decreasing since at least the mid1950s (Fig. 4A) and since at least 1970 for the younger trees ( $<50$ years) (Fig. 4B). A graph based on all trees (Fig. 4C) looks essentially like Fig. 4B since 1950, and this is expected given that nearly $70 \%$ of the trees originated in the 1950s and 1960s (Fig. 3).

Graphs of individual tree radial increment can provide additional information beyond that provided by the mean growth curves. Unstratified averaging of radial increments can mask important differential growth patterns that exist within the sample. Often these different growth patterns are related to important stand history events (Reams and Huso 1990; Reams and Van Deusen 1993). The desire for an objective procedure to classify trees with similar growth patterns lead to the following cluster analysis.

In the absence of historical stand-level (i.e., plot) data to document past disturbances it seems reasonable to assume that the younger trees originated on old fields or clearcuts in the 1950s and 1960s. These younger trees may exhibit different types of radial growth patterns than the older trees. To evaluate this assumption trees were stratified into two groups; those $<50$ and the others 250 years old.

Orthogonal polynomials of degree two, three, four were fit to ring-width series to illuminate the various radial growth patterns over the last 30 years (1960-1989) for the two age-classes of trees. The degree of polynomial needed is influenced by two immediately apparent factors: (1) the length of the time series (e.g., number of annual rings), (2) the smallest interval over which detection of an increase or decrease function of radial growth is desired. For example, a second-degree model can be concave up 
Fig. 5. Thirty-year (1960-1989) radial growth curves of trees greater than 50 years old. Each curve is estimated by a fourth-degree orthogonal polynomial. Row I, column 1 is the medoid for each cluster. Maximum and minimum ring widths determine the $\mathrm{v}$-axis for each plot.

\section{Cluster 1}
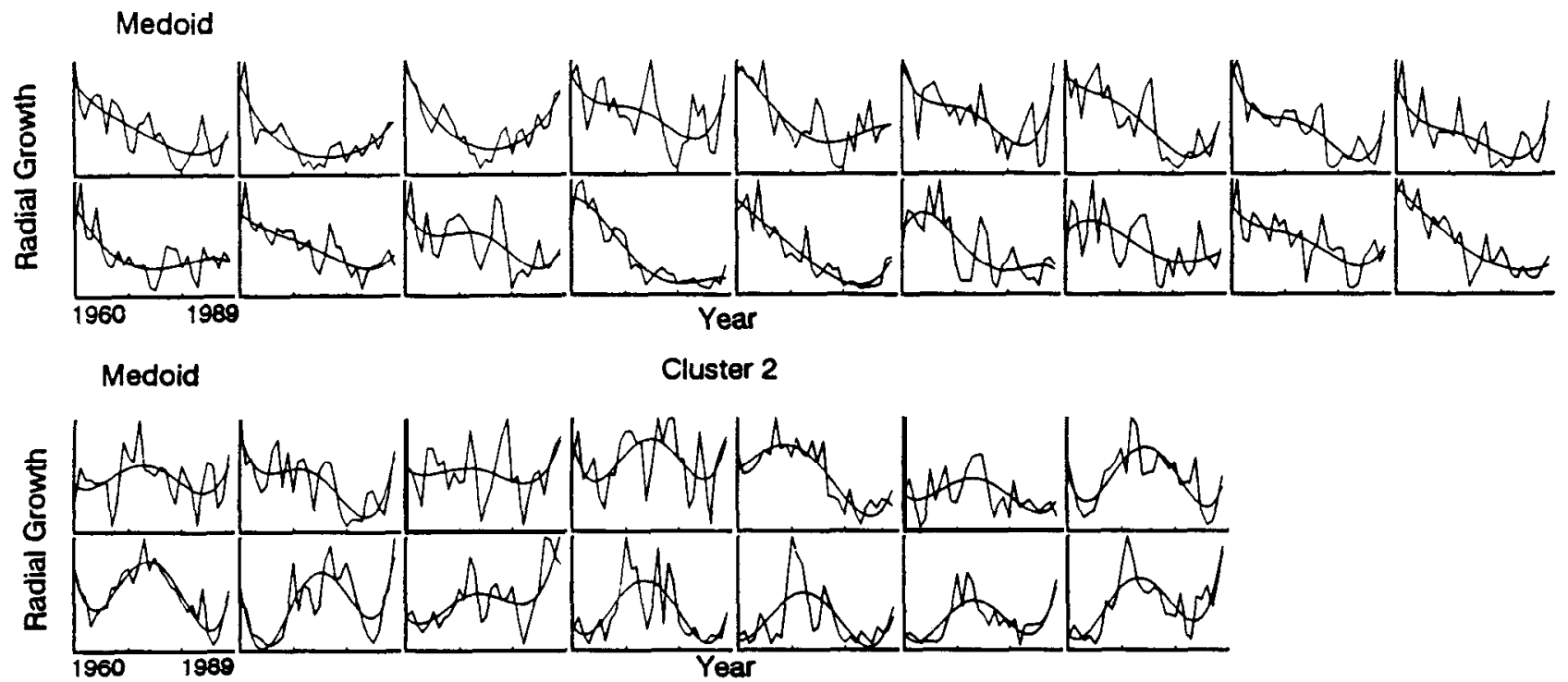

Medoid

Cluster 3

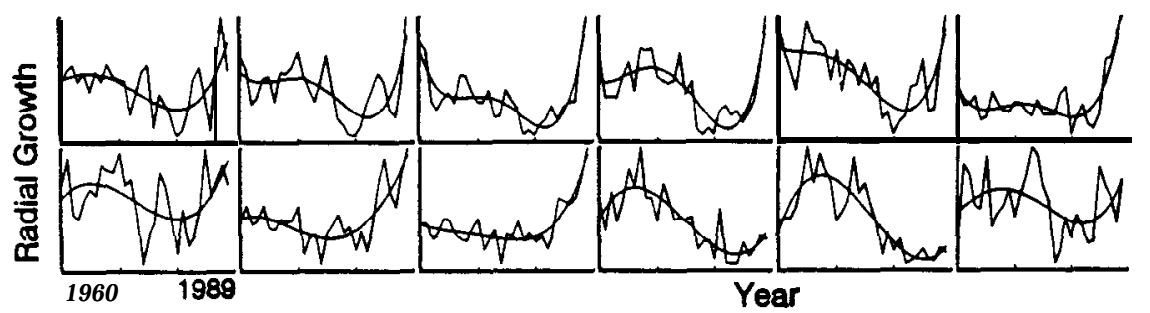

or down but has no inflection point. A third-degree model can have one inflection point that separates a concave up (down) from a concave down (up) portion of a function. A fourth-degree model can have two inflection points thereby separating several concave up or down portions of a function. This latter type of curve form was the most complex encountered for the 30-year period in question, therefore a fourth-degree model was the highest order model fit to an individual ring-width series.

Graphical displays overlaying the polynomial fit to each radial growth series for trees greater than 50 years old (Fig. 5) indicate that nearly all trees exhibit a 1970s radial growth reduction. Since the early 1980s nearly all trees greater than 50 years old show an increase in radial growth through 1989, the last year of complete annual ring formation collected in this study.

Results of the cluster analysis based on the orthogonal coefficients fit to each ring-width series greater than 50 years old indicates that at least three general growth patterns reside in these data over the last 30 years (Fig. 5). The medoid (representative growth curve) for each cluster captures the general growth pattern of the trees assigned to that specific group.

The medoid and individual growth functions for cluster 1 (Fig. 5) are concave up and can be represented by fitting a second-degree polynomial. The medoid and individuals of cluster 2 (Fig. 5) can be approximated with a fourth-degree polynomial indicative of a cyclic growth function. The decades of the 1960s and 1980s exhibit increasing growth, and the 1970s decreasing growth resulting in the function being concave down over the 1960s and 1970s and concave up from the 1970s through 1980s. Cluster 3 (Fig. 5) is concave up over the last 20 years with radial growth of this group represented by a third degree polynomial.

In the interest of data reduction, which is one of the benefits of cluster analysis, graphical displays of the polynomial fits and cluster analysis for the 148 ring-width series of the younger trees are restricted to the medoids of each cluster (Fig. 6). The most obvious difference between the older (Fig. 5) and younger (Fig. 6) group of trees is the greater complexity of increment patterns and therefore need of a higher degree polynomial in modeling radial growth of the older group of trees.

It appears that a second-degree polynomial provides an adequate fit to the younger trees (column 1, Fig. 6). That is neither the ends nor the midsection of the data appear to be under or over fit by the polynomial. However, using a second-degree model portrays a general leveling off of radial growth and does not capture the decadal increase of the 1980s. The medoids based on orthogonal polynomials of 
Fig. 6. Thirty-year (1960-1989) radial growth curves of trees less than 50 years old. Rows are clusters. columns are the degree polynomial used to estimate radial growth. The number in the upper right-hand corner for each panel is the percentage of trees represented by each medoid. Maximum and minimum ring widths determine the y-axis for each plot.

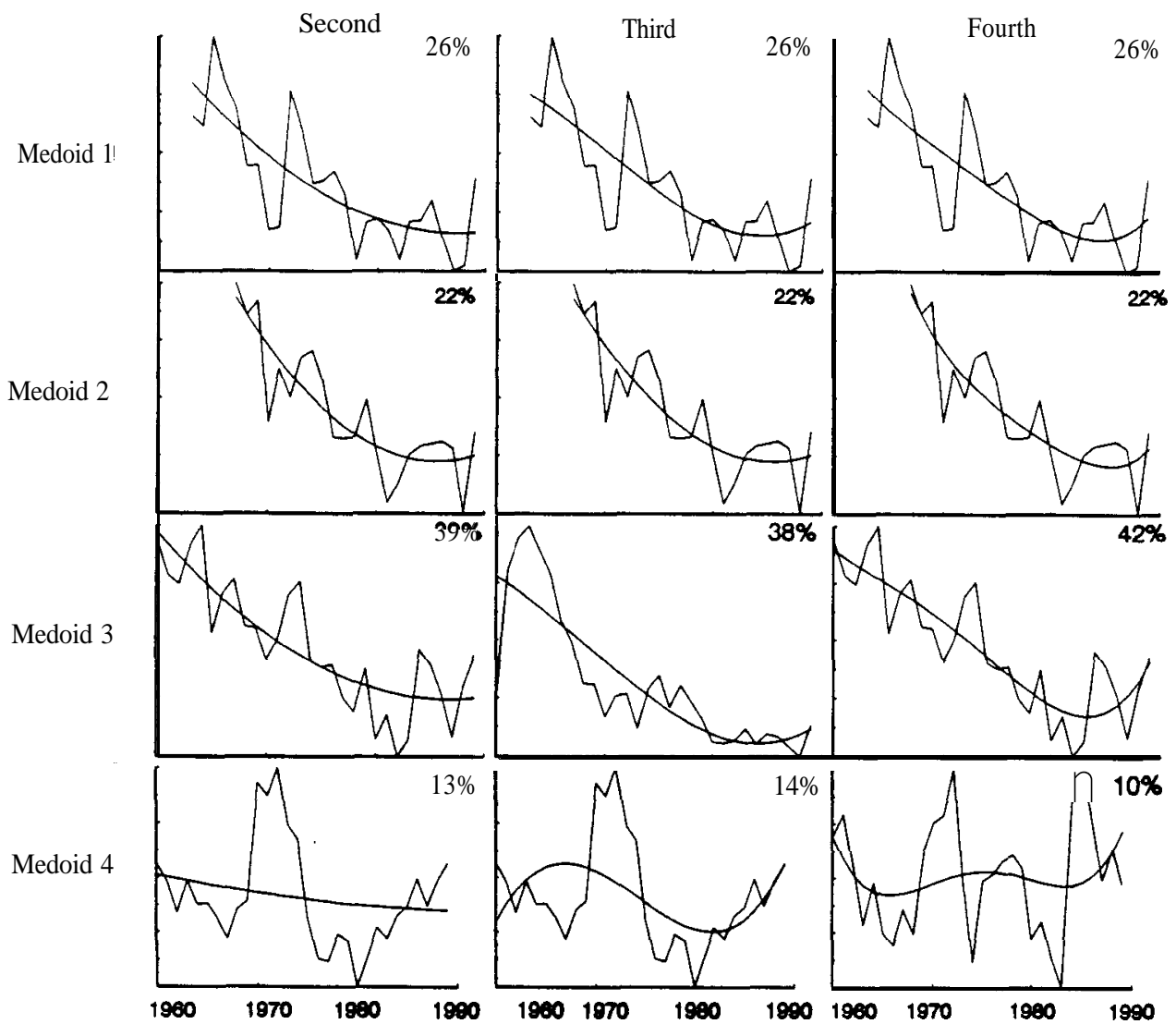

degree three and four are more flexible and do capture the increase of the 1980s. With the exception of cluster 4, which represents between 10 and 14\% (depending on the degree of the polynomial) of the trees, all other trees represented by clusters 1 through 3 are variations of a reversed-J curve.

\section{Discussion}

Although there are obvious long-term differences in radial growth patterns between the older (Fig. 5) and younger (Fig. 6) trees there is considerable consistency in trend over the last two decades. Nearly all trees, young (Fig. 6) and old (Fig. 5) have reduced radial growth in the 1970s and increased radial growth in the 1980s. Reductions in radial growth during the 1970s and early 1980s for the Virginia 20/20 study are coincident in time with FIA estimates of radial growth reductions for the Virginia Coastal Plain (Fig. 1), and with other loblolly pine growth declines reported in various parts of the southeast (Sheffield et al. 1985; Zahner et al. 1989; Ruark et al. 1991; Bechtold et al. 199 1; Van Deusen 1992a). Increased radial growth during the 1980s for loblolly pines (Figs. 4, 5, 6) in the Virginia 20/20 study corroborate the trend of increased net annual growth of softwood growing stock reported from the most recent (1990) FIA survey for Virginia Coastal Plain (Thompson 1991).

That radial growth has increased in the 1980s when compared with the 1970 s is corroborated by two sources of information. One source is that provided by FIA estimates of temporal change in radial growth (Fig. 1). The other source of change in radial growth is provided by the Virginia 20/20 study (Figs. 4, 5, 6). That the change in growth rate from the FIA sample is determined by comparing separate sets of trees (sample plots change from one survey cycle to the next) is particularly noteworthy. In contrast the change in growth rate identified from the Virginia 20/20 study is based on tracking radial increment for the same set of trees. Such findings diminish the likelihood that the change in growth is an artifact of sampling two separate sets of trees from one survey cycle to the next.

Over the last decade three possible causes have been emphasized in attempts to explain the 1970s through early 1980s reductions in radial increment of loblolly pine. This list includes: (1) the possible role of air pollutants, specifically tropospheric ozone $(0$,$) ; (2) climate variation, in$ particular drought: and (3) stand dynamics. Some preliminary and conjectural observations addressing possible causes 1 through 3 follow. 
Fig. 7. Palmer drought severity index by month for the Virginia Coastal Plain from 1970 to 1989.

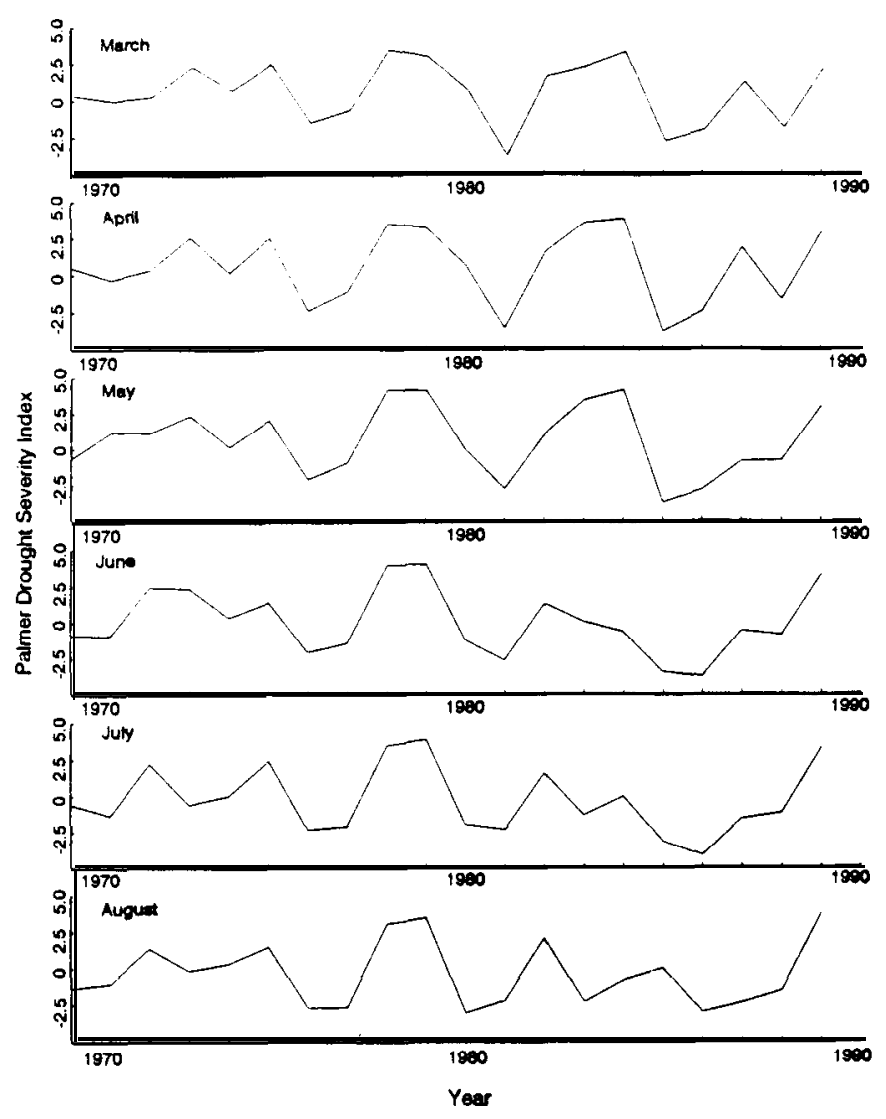

Ozone

Ambient 0, exposures have caused growth reductions in some tree genotypes in some areas of the United States (Lefohn and Lucier 1991). Furthermore results of exposureresponse experiments indicate that $\boldsymbol{O}_{3}$ at ambient concentrations can alter the growth and physiology of southern pine seedlings (NAPAP 1990). Whether ambient levels of 0 , are responsible for the 1970 s reduction in loblolly pine radial increment is unknown. This is because limited monitoring data from forested sites exist and additional exposure data are needed to support development of realistic exposure-response experiments and interpretation of experimental results (Lefohn and Lucier 1991).

Although it is not possible to directly match a meaningful 0 , exposure to tree response the following observation is offered. The decadal increase in growth of the 1980s reported here seems to put in question the likelihood that 0 , exposure explains recent trends in loblolly pine growth. The overall national trend in photochemical oxidants and their precursors have steadily increased from 1900 through 1980 (US EPA 1985). Unusually high levels of 0 , were produced in the southeastern United States in 1983 and 1988 (Lefohn and Shadwick 1991). Lefohn and Shadwick (1991) state that warmer than normal summer temperatures in 1983 and 1988 were responsible for high levels of 0 , rather than any apparent increases in 0 , precursors. Apparently the growth increase documented in the Virginia Coastal Plain throughout the 1980s happened with no appreciable decrease in 0 ,.

\section{Drought}

That drought can severely limit diameter growth of southem pines has been known since the 1930s (Lodewick 1930; Coile 1936). Zahner (1963, 1968) found that earlywood growth is intrinsically uniform, while latewood growth is strongly regulated by the immediate, current moisture conditions. More recently, numerous studies have further quantified the effect of summer drought on decreased radial growth of loblolly pine (Cregg et al. 1988; Friend and Hafley 1989; Zahner et al. 1989; Jordan and Lockaby 1990: Houle and Delwaide 1991) throughout most of its range.

Raw climate variable such as precipitation and temperature rarely adequately describe the growth conditions experienced by plants in space and time. The Palmer drought severity index (PDSI) was developed to indicate the relative magnitude of prolonged deviations from normal soil moisture availability for agricultural systems at a specific location (Palmer 1965). The PDSI incorporates the station latitude, estimated water-holding capacity of the soil, monthly precipitation, and average monthly temperatures to calculate an index of the resulting soil moisture availability. The PDSI uses site-specific coefficients to achieve comparability across sites, with a given index value representing intensity of water stress relative to what the site characteristically experiences. Because the procedure uses both antecedent and current weather data to establish the current moisture condition there is strong autocorrelation from month to month. A PDSI value of 0 indicates that current soil moisture availability is normal. Values of PDSI greater than 0 give relative wetness conditions, and values less than 0 give relative drought condition.

Stahle and Cleaveland (1992) have found that southeastern (North Carolina, South Carolina. Georgia) spring and summer rainfall averages are uncorrelated from 1892-1982, but the 20 wettest (driest) springs are usually followed by much drier (wetter) summers. Whether this inverse relationship between spring and summer rainfall exists for the Virginia Coastal Plain is unknown. However it does appear that spring and summer PDSI values for the Virginia Coastal Plain are serially correlated, with no indication of an inverse relationship between spring and summer PDSI since 1970 (Fig. 7).

Trends in spring through summer (March-August) PDSI since 1970 for the Virginia Coastal Plain indicate that moisture stresses were generally higher in the 1980s than the 1970s for the Virginia Coastal Plain (Fig. 7). It seems unlikely that increased drought stress in the 1980s would lead to a change in radial growth trend from declining throughout the 1970s to increasing in the 1980s. It is especially illuminating to note that strongest spring and summer drought from 1970-1989 occurs in 1985 and 1986 (Fig. 7) in the midst of a growth increase (Figs. 1, 4, 5, 6).

\section{Stand dynamics}

Besides stand origin and age, competition is an important stand dynamics variable that influences radial growth. Both open grown trees and trees undergoing among-tree competition will often display a negative exponential function 
or reversed-1 growth pattern. Increases in radial growth for mature trees are often associated with disturbances that result in reductions of competition, essentially resulting in a thinning effect for the residual trees (Lorimer 1985; Reams and Van Deusen 1993).

Research based on FIA data from the Coastal Plain of North Carolina indicates the regional frequency of disturbance can be significant. Wyant et al. (1991) report that nearly half of the naturally regenerated stands in the sand, flatwood, and upland physiographic classes and about a quarter of the stands in the remaining physiographic classes experienced disturbances during a lo-year period. Obviously, methods of analyses must be developed for identification of radial growth patterns that result from various disturbance regimes. Clustering methods such as those presented in this paper can be used to identify growth patterns that are related to different disturbance events (Reams and Van Deusen 1993).

Ideally an investigation of changes in forest productivity should use total stand growth as the response variable because stand growth is closely related to the physical environment. Unfortunately the data for this study are based on initial plot establishment and only a subset of dominant and codominant trees on each plot were sampled for radial increment, thus calculation of total stand growth is not possible. Fortunately growth rates and trends based on a carefully selected subset of trees can give surprisingly good estimates of stand increment (Garcia 1992).

Because 1989 is the initial year of the Virginia 20/20 study plot establishment, stand history information that is traditionally obtained by plot remeasurement on a multiyear interval is unavailable. This makes it difficult to directly test whether stand dynamics explains the recent surge in radial growth. However, the observed radial growth trends provide evidence that can be interpreted as supportive of stand dynamics effects.

The young class $(<50$ years) of trees of which $85 \%$ originated in the 1950 s and 1960 s show the reversed-J radial growth patterns that are typical of trees growing in an increasing competitive environment (Fig. 6). The most interesting feature portrayed by these trees is the recent radial growth increase. Such a reversal in growth trend would be expected for trees that have emerged as survivors from a wave of mortality during the stem exclusion stage of stand development (Oliver and Larson 1990). The growth and mortality trends from FIA data for the Coastal Plain of Virginia appear to support this contention. FIA surveys indicate that mortality rates increased in both the 1966-1976 and 1977-1985 survey cycles, while growth decreased (Cost 1976; Brown and Craver 1985; Bechtold et al. 1987). The situation reversed in the 1986-1991 survey cycle with growth increasing and mortality decreasing (Thompson 1991). These results corroborate Garcia's (1992) conclusion that radial growth estimates from a reasonably selected subset of trees can provide good estimates of total stand increment.

The older class ( $>50$ years) of trees display more variable growth patterns with one group of trees displaying in general a flattened reversed-J growth function, and two groups of trees displaying a 1960s growth surge, a 1970s decrease followed by another growth surge in the $1980 \mathrm{~s}$
(Fig. 5). Growth patterns portrayed by clusters 2 and 3 (Fig. 5) from 1960-1980 are similar to those found by Van Deusen (1992a) for natural loblolly pine growing in the Piedmont regions of Georgia and South Carolina. One possible scenario is that rapid growth occurred in 1960s until canopy closure and increasing competition caused growth to decline in the 1970s and early 1980s (Van Deusen $1992 a$ ). Reductions in competition through self-thinning or other events could be related to increased radial increment throughout the 1980s.

Because growth measurements are from trees that are currently dominant or codominant, there is the possibility that the crown class of some of these trees may have been different in the past. Trees moving from the lesser crown classes to the dominant or codominant class would result in increasing growth trends in subsequent years. For loblolly pine such events are mostly likely an expression of stand differentiation (Oliver and Larson 1990) rather than an artifact of sampling. Loblolly pine is moderately tolerant to shading when young but becomes increasingly intolerant with age, and is most accurately classed as intolerant (Baker and Langdon 1990). Only rarely does a tree in the lower crown classes latently emerge to the upper crown classes in single-species, single-cohort stands (Oliver and Larson 1990).

That loblolly pines in excess of 50 years old are capable of such a strong growth surge is somewhat surprising. The species is widely believed to be incapable of responding to reductions in competition at this age, and whether this is the reason for the growth increase is conjectural because disturbance information is not available. However, the growth response seen in this study appears to be consistent with the finding by Guldin and Fitzpatrick (1991) that loblolly pine can respond to release at advanced ages. The age at which loblolly diameter growth fails to respond to reductions in competition is not known, however Reynolds et al. (1984) report good response up to at least age 30 years.

\section{Conclusions}

This study reports the first update of radial growth trends for loblolly pine since discussions of the southern pine growth decline debate began in the 1980s. Nearly all trees sampled in this study confirm the 1970s radial growth reduction first reported by Sheffield et al. (1985). A reversal in trend has occurred since the early 1980s with radial growth increasing since then for both old and young trees. This change to increased growth corroborates the finding of increased stand level growth of loblolly pine identified in the most current Forest Inventory and Analysis (FIA) survey cycle for the Virginia Coastal Plain. If the radial growth trends of loblolly pines growing in the Virginia Coastal Plain are in anyway indicative of growth in other parts of the southeastern United States it would appear that the southern pine growth decline has abated.

The trends of the older trees indicate that growth trends appear to be cyclic for the region. This conclusion is similar to that by Christensen and Peet (1988) for loblolly pines on the Duke Forest. They report that growth increment during 1965-1984 was less than from 1934-1965. However, since 1984, growth rates have increased. How frequently and 
for what duration growth inclines and declines for loblolly pine occur is unknown. Reams et al. (1993) reports that radial growth of red spruce (Picearubens Sarg.) has oscillated at least nine times over the last two centuries, with cycles most commonly spanning a period of about 20 years.

In the absence of traditional stand disturbance information, ring width growth patterns are often used to suggest different canopy disturbance histories for both individual trees and stands (Reams and Van Deusen 1993). Interpretations based on radial growth patterns suggest that of the possible list of explanations for these growth trends it appears that stand disturbances and subsequent stand dynamics events cannot be discounted and seem at least as probable as 0 , or summer drought stress.

\section{References}

Baker, J.B., and Langdon, O.G. 1990. Pinus taeda. In Silvics of North America. Edited by R.M. Burns and B.H. Honkala. U.S. Dep. Agric. Agric. Handb. 654. pp. 497-5 12.

Bechtold, W.A., Brown, M.J., and Tansey, J.B. 1987. Virginia's forests. U.S. For. Serv. Resour. Bull. SE-95.

Bechtold, W.A., Ruark, G.A., and Lloyd, F.T. 1991. Changing stand structure and regional growth reductions in Georgia's natural pine stands. For. Sci. 37: 703-717.

Brown, M.J., and Craver, G.C. 1985. Forest statistics for the Coastal Plain of Virginia, 1985. U.S. For. Serv. Resour. Bull. SE-80.

Christensen. N.L., and Peet, R.K. 1988. Patterns of growth and mortality of loblolly pine (Pinus taeda) in permanent sample plots of the Duke Forest: 1934-1988. Report to the Southern Commercial Forest Research Cooperative Program Manager. Duke University, Durham, N.C.

Coile, T.S. 1936. The effect of rainfall and temperature on the annual radial growth of pine in the southern United States. Ecol. Monogr. 6: 534-562.

Cost, N.D. 1976. Forest statistics for the Coastal Plain of Virginia. 1976. U.S. For. Serv. Resour. Bull. SE-34.

Cregg, B.M., Dougherty, P.M., and Hennessey, T.C. 1988. Growth and wood quality of young loblolly pine trees in relation to stand density and climatic factors. Can. J. For. Res. 18: 85 1-858.

Douglass, A.E. 1941. Crossdating in dendrochronology. J. For. 39: 825-831.

Friend, A.L., and Hafley, W.L. 1989. Climatic limitations to growth in loblolly and shortleaf (Pinus taeda and P.echinata): a dendroclimatological approach. For. Ecol. Manage. 26: 113-122.

Fritts, H.C. 1976. Tree rings and climate. Academic Press, London.

Garcia, 0. 1992. Sampling for tree-ring analysis. In Integrating forest information over space and time. Edited by G. Wood and B. Turner. ANUTECH Pty Ltd., Canberra, Australia. pp. 110-122.

Guldin, J.M., and Fitzpatrick, M.W. 1991. Comparison of log quality from even-aged and uneven-aged loblolly pine stands in South Arkansas. south. J. Appl. For. 15: 10-17.

Houle, G., and Delwaide, A. 1991. Population structure and growth-stress relationship of Pinus taeda in rock outcrop habitats. J. Veg. Sci. 2: 47-58.

Jordan, D.N., and Lockaby, B.G. 1990. Time series modelling of relationships between climate and long-term radial growth of loblolly pine. Can. J. For. Res. 20: 738-742.

Kaufmann, L.. and Rousseeuw, P.J. 1990. Finding groups in data: an introduction to cluster analysis. John Wiley \& Sons, New York.
Lefohn, A.S.. and Lucier. A.A. 1991. Spatial and temporal variability of ozone exposure in forested areas of the United States and Canada: 1978-1988. J. Air Waste Manage. Assoc. 41: $694-701$.

Lefohn. A.S., and Shadwick. D.S. 1991. Ozone, sulfur dioxide. and nitrogen dioxide trends at rural sites located in the United States. Atmos. Environ. 25A(2): 49 1-501.

Lodewick, J.E. 1930. Effect of certain climatic factors on the diameter growth of longleaf pine in western Florida. J. Agric. Res. 41: 349-363.

Lorimer. C.G. 1985. Methodological considerations in the analysis of forest disturbance history. Can. J. For. Res. 15: 200-213.

Lucier, A.A. 1988. Pine growth-rate changes in the Southeast: a summary of key issues for forest managers. South. J. Appl. For. 12: 84-89.

NAPAP. 1990. Acidic deposition: State of Science and Technology Reports 16, 17, \& 18. National Acid Precipitation Program, 1990 Integrated Assessment Report. 722 Jackson Place, NW Washington, DC 20503.

Oliver, C.D., and Larson, B.C. 1990. Forest stand dynamics. McGraw-Hill, New York.

Palmer, W.C. 1965. Meteorological drought. U.S. Department of Commerce Weather Bureau. Res. Pap. 45. Government Printing Office, Washington, D.C.

Ramsay, J.O., and Dalzell, C.J. 1991. Some tools for functional data analysis. J. R. Stat. Soc. B, 53: 539-572.

Reams, G.A.. and Huso, M.M.P. 1990. Stand history: an alternative explanation of red spruce radial growth reduction. Can. J. For. Res. 20: 250-253.

Reams, G.A., and Van Deusen. P.C. 1993. Synchronic largescale disturbances and red spruce growth decline. Can. J. For. Res. 23: 1361-1374.

Reams, G.A., Nicholas, N.S., and Zedaker. S.M. 1993. Two hundred year variation of southem red spruce radial growth as estimated by spectral analysis. Can. J. For. Res. 23: 291-301.

Reynolds, R.R., Baker, J.B., and Ku, T.T. 1984. Four decades of selection timber management on the Crossett Farm Forestry Forties. Ark. Agric. Exp. Stn. Bull. 872.

Riitters, K., Papp, M., Cassell, D., and Hazard, J. 1991. Forest health monitoring plot design and logistics study. U.S. Environ. Prot. Agency Res. Dev. Rep. EPA/600/S3-91105 1.

Roesch, F.A. 1995. Design and analysis for detection monitoring of forest health. In The Monte Verita Conference on Forest Survey Designs: "Simplicity Versus Efficiency" and Assessment of Non-Timber Resources. 2-7 May 1994, Monte Verita, Ascona, Switzerland. Edited by M. Kohl, P. Bachmann, P. Brassel, and G. Preto. Swiss Federal Institute for Forest, Snow and Landscape Research, Birmensdorf, Switzerland. pp. 281-289.

Ruark, G.A.. Thomas, C.E., Bechtoid, W.A.. and May, D.M. 1991. Growth reductions in naturally regenerated pine stands in Alabama and Georgia. South. J. Appl. For. 15: 73-79.

Schreuder, H.T., and Thomas, C.E. 1991. Establishing causeeffect relationships using forest survey data. For. Sci. 37: 1497-1512.

Sheffield, R.M., Cost, N.D., Bechtold, W.A., and McClure, J.P. 1985. Pine growth reductions in the Southeast. U.S. For. Serv. Resour. Bull. SE-83.

Stahle, D.W., and Cleaveland, M.K. 1992. Reconstruction and analysis of spring rainfall over the southeastern U.S. for the past 1000 years. Bull. Am. Meteorol. Soc. 73: 1947-1961.

Thompson, M.T. 1991. Forest statistics for the Coastal Plain of Virginia, 1991. U.S. For. Serv. Resour. Bull. SE-122.

USEPA. 1985. Historic emissions of sulfur and nitrogen oxides in the United States from 1900-1980. U.S. Environmental Protection Agency, Washington, D.C. 
Van Deusen, P.C. 1992a. Growth trends and stand dynamics in natural loblolly pine in the southeastern United States. Can. J. For. Res. 22: 660-666.

Van Deusen, P.C. 19926. Dynaclim, version 3.2. Institute for Quantitative Studies, Southern Forest Experiment Station, USDA Forest Service, New Orleans, La.

Wyant. J.G, Alig, R.J., and Bechtold, W.A. 1991. Physiographic position. disturbance and species composition in North Carolina coastal plain forests. For. Ecol. Manage. 41: I-19.
Zahner, R. 1963. Internal moisture stress and wood formation in conifers. For. Prod. J. 13: 240-247.

Zahner, R. 1968. Water deficits and growth of trees. In Water deficits and plant growth. Vol. II. Edited by T.T. Kozlowski. Academic Press, New York. pp. 191-254.

Zahner, R., Saucier, J.R.. and Myers, R.K. 1989. Tree-ring model interprets growth decline in natural stands of loblolly pine in the southeastern United States. Can. J. For. Res. 19: $612-621$ 